\title{
Voltammetric and impedance studies of inosine-5'-monophosphate and hypoxanthine
}

\author{
Ana Maria Oliveira-Brett ${ }^{\mathrm{a}, *}$, Luís A. Silva ${ }^{\mathrm{a}}$, Giosi Farace ${ }^{\mathrm{b}}$, \\ Pankaj Vadgama ${ }^{\mathrm{b}}$, Christopher M.A. Brett ${ }^{\mathrm{a}}$

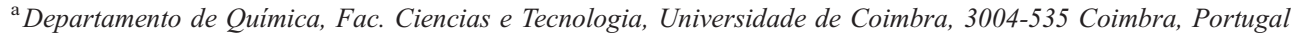 \\ ${ }^{\mathrm{b}}$ IRC in Biomedical Materials, Queen Mary University of London, Mile End Road, London E1 4NS, UK
}

Received 16 October 2002; received in revised form 20 November 2002; accepted 22 November 2002

\begin{abstract}
The oxidation mechanism and adsorption of inosine 5'-monophosphate and hypoxanthine were investigated in solutions of different $\mathrm{pH}$ using voltammetric and impedance methods at glassy carbon electrodes. For both compounds, the $\mathrm{pH}$ dependence from differential pulse voltammetry showed that the same number of electrons and protons are involved in the rate-determining step of the electrochemical reaction. In the case of hypoxanthine, it was also possible to study the effect of different concentrations. At high concentrations of hypoxanthine, two oxidation peaks were observed, the first due to hypoxanthine oxidation with formation of oligomers and the second due to hypoxanthine oligomer oxidation, both compounds adsorbing strongly. Impedance measurements corroborated the voltammetric results and enabled the study of the adsorption of hypoxanthine on glassy carbon.
\end{abstract}

(C) 2003 Elsevier Science B.V. All rights reserved.

Keywords: Inosine 5'-monophosphate; Hypoxanthine; Electrochemical adsorption; Differential pulse voltammetry; Electrochemical impedance; DNAbiosensor

\section{Introduction}

The study of the electrochemical oxidation and reduction processes of biological compounds is very important, and it may lead to the elucidation of alternative methods for their detection and analysis. The investigation of these redox processes also provides considerable insight into the interactions of these molecules within complex biological systems.

Inosine and hypoxanthine are both derived from the decomposition of adenosine triphosphate (ATP), this sequence being particularly relevant following death in fishes [1].

$\mathrm{ATP} \rightarrow \mathrm{ADP} \rightarrow \mathrm{AMP} \rightarrow \mathrm{IMP} \rightarrow \mathrm{HxR} \rightarrow \mathrm{Hx} \rightarrow \mathrm{X} \rightarrow \mathrm{U}$

where ADP is adenosine diphosphate, AMP adenosine 5'monophosphate, IMP inosine 5'-phosphate, HxR is inosine, Hx hypoxanthine, $\mathrm{X}$ xanthine and $\mathrm{U}$ uric acid.

\footnotetext{
* Corresponding author. Tel.: +351-239-835295; fax: +351-239835295.

E-mail address: brett@ci.uc.pt (A.M. Oliveira-Brett).
}

The structure of IMP is shown below

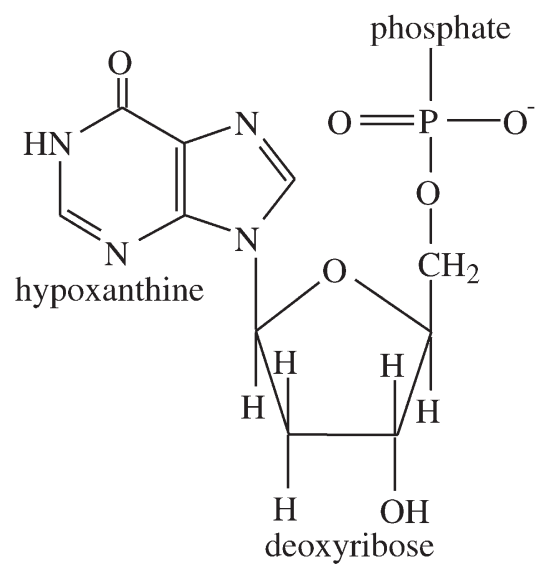

and clearly shows the purine base, hypoxanthine (Hx), together with the deoxyribose and phosphate groups.

Electrochemical studies of the reduction of inosine and hypoxanthine carried out at mercury electrodes showed better defined reduction peak currents in acid $\mathrm{pH}[2,3]$. In alkaline conditions, hypoxanthine was not reduced [2]. It was also found that hypoxanthine forms a condensed film at 
the mercury-electrolyte interface [4]. Procedures for $\mathrm{Hx}$ and IMP determination were developed using adsorptive stripping voltammetry of the purines [5] and of their $\mathrm{Cu}(\mathrm{II})$ complexes $[6,7]$.

In recent years, most studies on these compounds have been carried out with the aim of obtaining quantitative measurements of both inosine and hypoxanthine via oxidation. Sensors have been developed using microelectrodes [8], chemically modified electrodes $[9,10]$ and by mechanical or electrochemical activation of the electrode surfaces $[11,12]$. However, most of the reported research has used oxidase-based enzyme biosensors for hypoxanthine detection with measurement of oxygen consumption or product formation [13-25]. Although many of the systems developed also permit the measurement of other species in the decomposition chain, only in a few cases $[13,24,25]$ are the signals due to IMP and HxR also considered. Both Ghosh et al. [20] and Okama and Watanabe [25] described a freshness indicator based on the ratio

$\{(\mathrm{HxR}+\mathrm{Hx}) /(\mathrm{IMP}+\mathrm{HxR}+\mathrm{Hx})\}$

It was therefore necessary to develop a system capable of measuring all three compounds.

The electrochemical activity of nucleosides and nucleotides is normally found in the heterocyclic ring (base) and this should thus also be the case for IMP and Hx. The deoxyribose group has an influence on the $\mathrm{p} K_{\mathrm{a}}$ value and solubility: the $\mathrm{p} K_{\mathrm{a}}$ for protonated inosine is 1.2 , while that for hypoxanthine is 1.98 [26]. Other differences between IMP and $\mathrm{Hx}$ can be expected to arise from the influence of the deoxyribose and phosphate groups on molecular size, reflected in diffusion rates, on adsorption and on the electron density in the active site. Such effects will be manifested by the shifting of the oxidation and reduction potentials and in the observed currents.

The oxidation mechanism of hypoxanthine, which involves the loss of two electrons and two protons, probably follows the same route as that described for guanine [27]. The fact that hypoxanthine does not have the amino group in position 2 of the purinic ring, as in the case of guanine, should not influence the mechanism of electron transfer. Electrochemical studies with hypoxanthine have shown fast and strong adsorption on pyrolytic graphite electrodes $[28,29]$.

A detailed electrochemical study of hypoxanthine and inosine $5^{\prime}$-phosphate will help to understand the oxidation mechanism and adsorption of purine bases and purine nucleosides. Improved knowledge in this field will aid the development of DNA-biosensors [30-32] and help in explaining oxidative damage caused to DNA from health hazard compounds. The work presented in this paper probes the influence of the deoxyribose-phosphate substituent on the oxidation behaviour of hypoxanthine at different $\mathrm{pH}$ values, and also the phenomenon of adsorption of hypoxanthine on the glassy carbon electrode surface. Electro-
Table 1

Buffer and background electrolyte solutions, concentration $0.1 \mathrm{M}$

\begin{tabular}{ll}
\hline $\mathrm{pH}$ & Composition \\
\hline 1.0 and 2.0 & $\mathrm{KCl}+\mathrm{HCl}$ \\
$3.4-5.4$ & $\mathrm{NaOAc}+\mathrm{HOAc}$ \\
$6.1-8.1$ & $\mathrm{Na}_{2} \mathrm{HPO}_{4}+\mathrm{NaH}_{2} \mathrm{PO}_{4}$ \\
9.3 & $\mathrm{Na}_{2} \mathrm{~B}_{2} \mathrm{O}_{7} \cdot 10 \mathrm{H}_{2} \mathrm{O}+\mathrm{NaOH}$ \\
12.2 and 13.1 & $\mathrm{KCl}+\mathrm{NaOH}$ \\
\hline
\end{tabular}

chemical impedance is used for the first time to probe the adsorption and oxidation of hypoxanthine and inosine $5^{\prime}$ phosphate at the electrode surface.

\section{Experimental}

All chemical reagents used were of analytical grade; DNA Calf Thymus (sodium salt, type I), inosine 5'-monophosphate and hypoxanthine were obtained from Sigma. All solutions were prepared using high-purity water (Milli-Q, Millipore, resistivity $>18 \mathrm{M} \Omega \mathrm{cm}$ ). All experiments were performed in buffer solutions of ionic strength $0.1 \mathrm{M}$ (see Table 1). The $\mathrm{pH}$ values of the electrolyte solutions were measured using a Crison pH-meter, model micropH 2001, and a combined Ingold glass electrode.

The working electrode used throughout the study was a glassy carbon disc of $6 \mathrm{~mm}$ diameter, the counter electrode was a platinum wire and the reference electrode a saturated calomel electrode (SCE), placed in a one-compartment cell.

All voltammetric experiments were carried out using an Autolab PGSTAT 10 potentiostat/galvanostat (Eco Chemie, Utrecht, Netherlands) equipped with an ECD low-current module. The conditions for differential pulse voltammetry were: pulse amplitude, $40 \mathrm{mV}$; pulse width, $70 \mathrm{~ms}$; scan rate, $5 \mathrm{mV} \mathrm{s}^{-1}$. For square wave voltammetry, the conditions were: frequency, $25-100 \mathrm{~Hz}$; pulse amplitude, 40 $\mathrm{mV}$; potential step, $5 \mathrm{mV}$ and for cyclic voltammetry: scan rate, $20-100 \mathrm{mV} \mathrm{s}^{-1}$ for IMP and $20-1000 \mathrm{mV} \mathrm{s}^{-1}$ for Hx.

Electrochemical impedance experiments were carried out with a Solartron 1250 Frequency Response Analyser coupled to a Solartron 1286 Electrochemical Interface with Zplot (Scribner Associates) control software. An rms perturbation of $10 \mathrm{mV}$ was applied and logarithmic frequency scans, five frequencies per decade, were performed over the frequency range $65 \mathrm{kHz}-0.01 \mathrm{~Hz}$. Fitting of impedance spectra was done using ZSim/CNLS impedance simulation and modelling software Version 4.1 (Scribner Associates).

\section{Results and discussion}

\subsection{Differential pulse voltammetry}

The electrochemical behaviour of IMP and Hx was investigated over the $\mathrm{pH}$ range $1.0-13.1$. Fig. 1 shows 
(a)
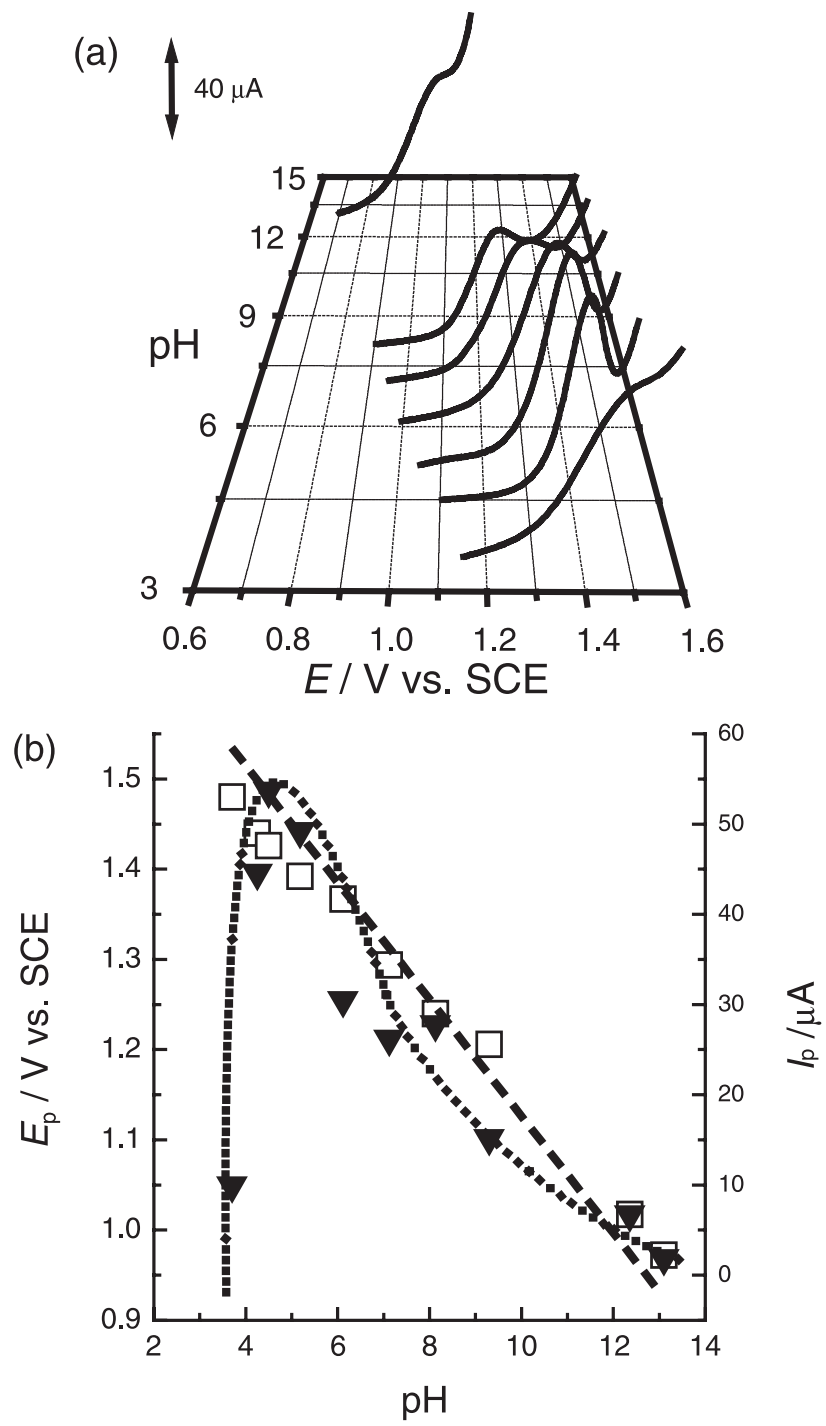

Fig. 1. Differential pulse (DP) voltammetry of $1 \mathrm{mM}$ IMP at different $\mathrm{pH}$ values. (a) DP voltammograms, scan rate $5 \mathrm{mV} \mathrm{s}^{-1}$, amplitude $50 \mathrm{mV}$; (b) plots of $(\square)$ peak potential, $E_{\mathrm{p}}$ vs. pH; (dashed line corresponds to $59 \mathrm{mV}$ per decade) and ( $\boldsymbol{\nabla})$ peak current, $I_{\mathrm{p}}$ vs. $\mathrm{pH}$.

differential pulse voltammograms for IMP and the corresponding variations of peak potential and peak current with $\mathrm{pH}$. Fig. 2 shows the same plots for $\mathrm{Hx}$. At $\mathrm{pH}$ values below 3.5, there was no evidence of any oxidation peak for IMP and in the case of $\mathrm{Hx}$, there was no peak at less than $\mathrm{pH}$ 2.5. In alkaline solution, from $\mathrm{pH} 9.3$ upwards, the oxidation wave corresponding to IMP overlapped with supporting electrolyte decomposition and thus could not be measured. The lower oxidation potential for Hx compared with IMP is similar to that found with guanine compared with guanosine and adenine compared with adenosine, where there is also introduction of sugar-phosphate groups [32]. Additionally, the currents for $\mathrm{Hx}$ oxidation are much larger - taking into account the difference in concentration, by a factor of 40 , paralleling the greater ease of oxidation.
For IMP, the slope of the $E_{\mathrm{p}}-\mathrm{pH}$ plot is $-50.7 \mathrm{mV}$ per $\mathrm{pH}$ unit over the whole $\mathrm{pH}$ range studied (Fig. 1b) which demonstrates that the number of protons and electrons involved in the oxidation mechanism is equal. For $\mathrm{Hx}$, the slope of the $E_{\mathrm{p}}-\mathrm{pH}$ plot is $-70.1 \mathrm{mV}$ per $\mathrm{pH}$ unit over the whole $\mathrm{pH}$ range studied, which again suggests that the reaction mechanism is similar to that observed for IMP, where the sugar-phosphate groups is the only difference.

Figs. $1 \mathrm{~b}$ and $2 \mathrm{~b}$ show clearly that the oxidation peak currents are largest at approximately weakly acid to neutral $\mathrm{pH}$. This therefore corresponds to a $\mathrm{pH}$ where the oxidation is easier. The oxidation of hypoxanthine may, like the oxidation of guanine, follow a two-step mechanism involving the total loss of four electrons and four protons $[25,26]$

(a)
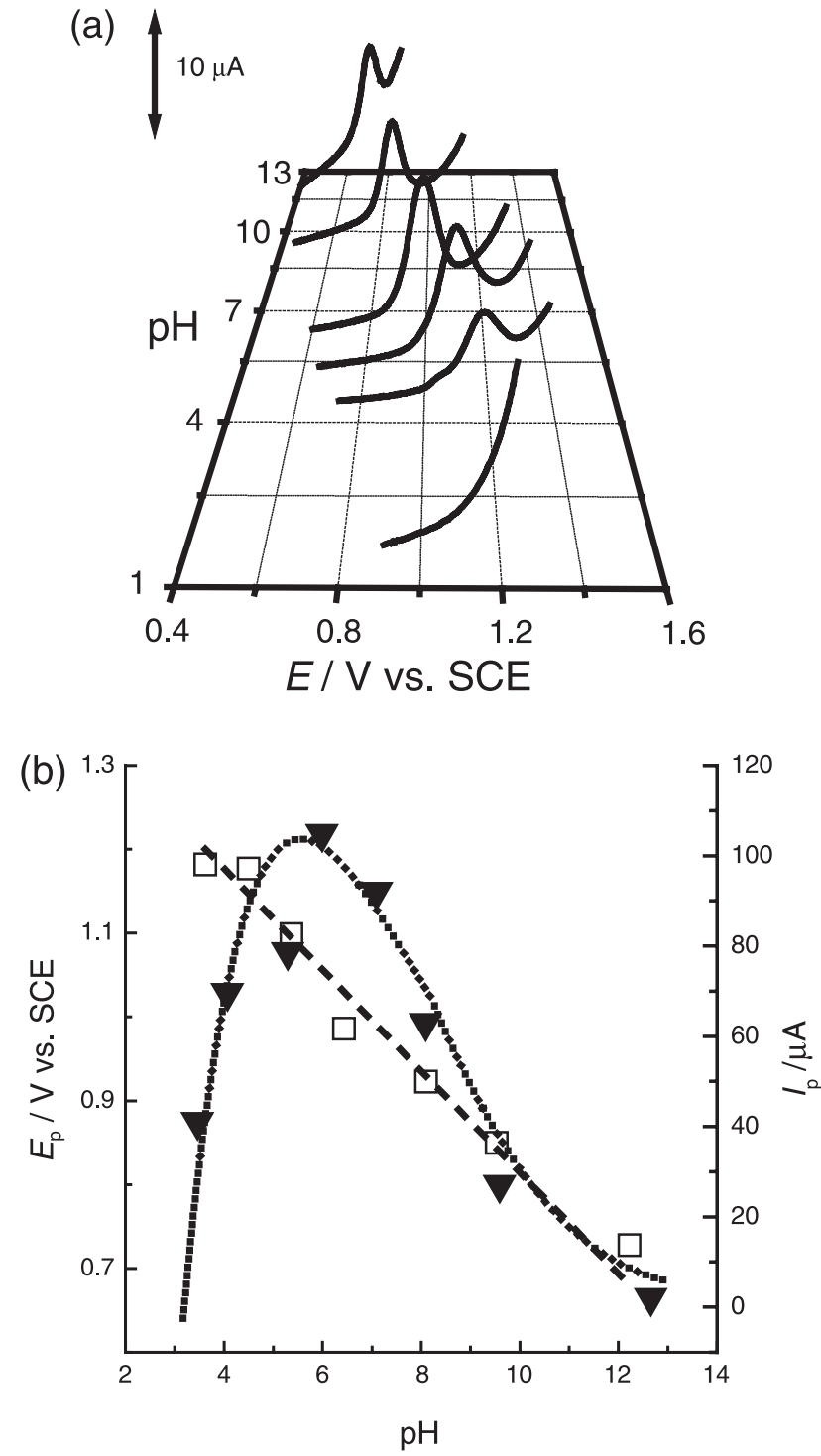

Fig. 2. Differential pulse (DP) voltammetry of $5 \times 10^{-5} \mathrm{M}$ hypoxanthine at different $\mathrm{pH}$ values. (a) DP voltammograms, scan rate $5 \mathrm{mV} \mathrm{s}^{-1}$, amplitude $50 \mathrm{mV}$; (b) plots of ( $\square$ ) peak potential, $E_{\mathrm{p}}$ vs. $\mathrm{pH}$; (dashed line corresponds to $59 \mathrm{mV}$ per decade) and $(\boldsymbol{\nabla})$ peak current, $I_{\mathrm{p}}$ vs. pH. 
and the oxidation mechanism of IMP is very similar. However, there is no proved mechanism as to where oxidation occurs first, at $\mathrm{C}_{2}$ or $\mathrm{C}_{8}$; xanthine is also a product of guanine deamination and uric acid is the final product. In both cases, the first $2 \mathrm{e}$ irreversible oxidation is the ratedetermining step.

Fig. 3 shows successive differential pulse measurements of IMP and Hx in acetate buffer electrolyte. The oxidation wave from IMP is close to the oxygen evolution wave at 1.4 $\mathrm{V}$ and increases slightly on successive scans. By contrast, the wave for hypoxanthine becomes markedly smaller on repeating the differential pulse scans and shifts to more positive potentials, reaching a value close to $+1.3 \mathrm{~V}$ vs. SCE; the first scan actually appears to be two overlapping peaks. This suggests that there is fast and strong adsorption of hypoxanthine onto the surface of the glassy carbon electrode, which blocks the surface accessibility.
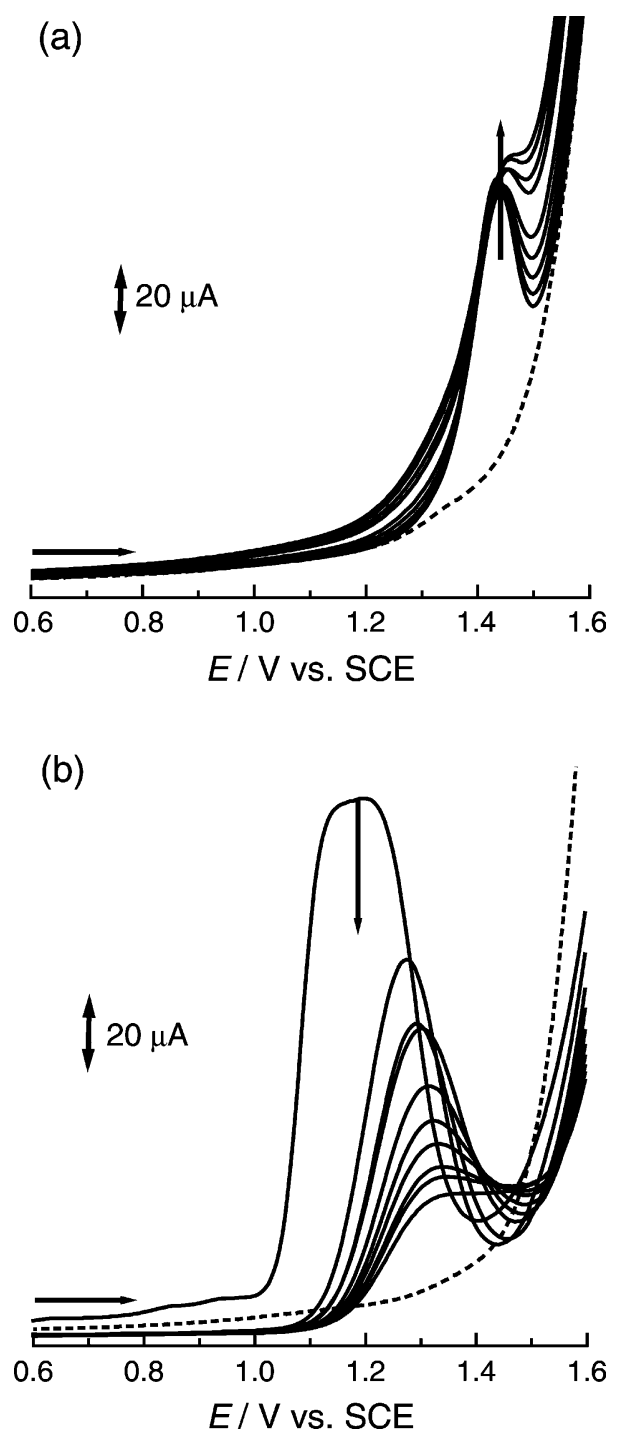

Fig. 3. Successive differential pulse voltammograms: (a) $1 \mathrm{mM}$ IMP and (b) $1 \mathrm{mM} \mathrm{Hx}$, in $0.2 \mathrm{M}$ acetate buffer ( $\mathrm{pH} 4.5$ ). Scan rate $5 \mathrm{mV} \mathrm{s}^{-1}$, amplitude $50 \mathrm{mV}$.

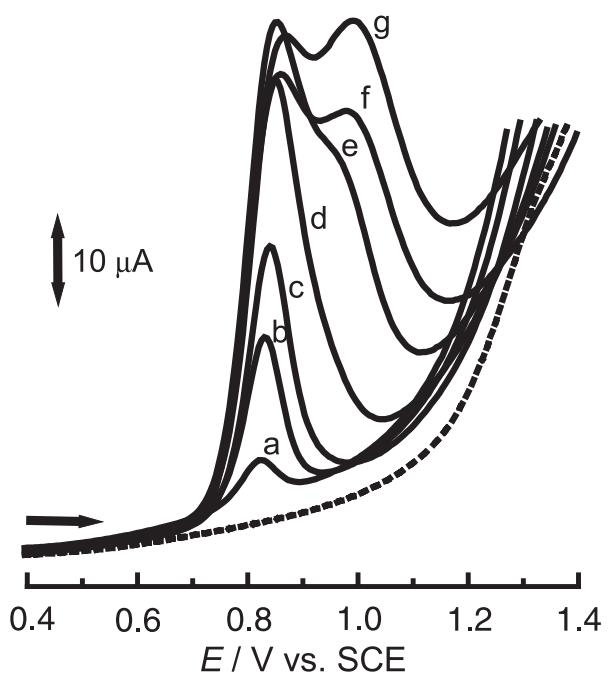

Fig. 4. Differential pulse voltammograms for hypoxanthine in $0.1 \mathrm{M}$ borate buffer (pH 9.3). Concentrations: (a) $1 \times 10^{-5}$; (b) $5 \times 10^{-5}$; (c) $1 \times 10^{-4}$; (d) $2.5 \times 10^{-4}$; (e) $5 \times 10^{-4}$; (f) $7.5 \times 10^{-4}$; (g) $1 \times 10^{-3}$ M. Scan rate $5 \mathrm{mV} \mathrm{s}^{-1}$, amplitude $50 \mathrm{mV}$.

The influence of hypoxanthine concentration is illustrated in Fig. 4 in borate buffer electrolyte. The peak occurs at a more negative potential owing to the higher $\mathrm{pH}$ of the solution. At concentrations above $0.5 \mathrm{mM}$, the main oxidation peak barely increases in magnitude, which is due to adsorption of $\mathrm{Hx}$, while the second peak which appears at a more positive potential and increases in magnitude in repeated scans, is probably due to oxidation of the adsorbed $\mathrm{Hx}$ oligomers. Indeed at lower concentrations, below 0.5 $\mathrm{mM}$, the asymmetry of the DPV peak is evidence that there is already a contribution from the oxidation of the adsorbing oligomers.

To determine if the two oxidation peaks observed for hypoxanthine were due to a unique process, successive differential pulse scans were made for high concentrations of hypoxanthine, with the final potential being set at a value before the second oxidation peak. In this case, there was a decrease in oxidation current and a shifting of the peak to more positive potentials. This is strong evidence for the importance of hypoxanthine oligomer adsorption.

\subsection{Square wave voltammetry}

The faster timescale of the potential scan in square wave voltammetry can be advantageous in investigating the alterations in the electrode process that can occur due to adsorption on the surface of the glassy carbon electrode. Fig. 5 shows square wave voltammograms for Hx and Fig. 6 for IMP oxidation. In both cases, an increase in the oxidation current is observed with increasing frequency. These results are in agreement with those obtained through differential pulse voltammetry except that square wave voltammetry is more sensitive than differential pulse voltammetry for higher concentrations of hypoxanthine. Con- 

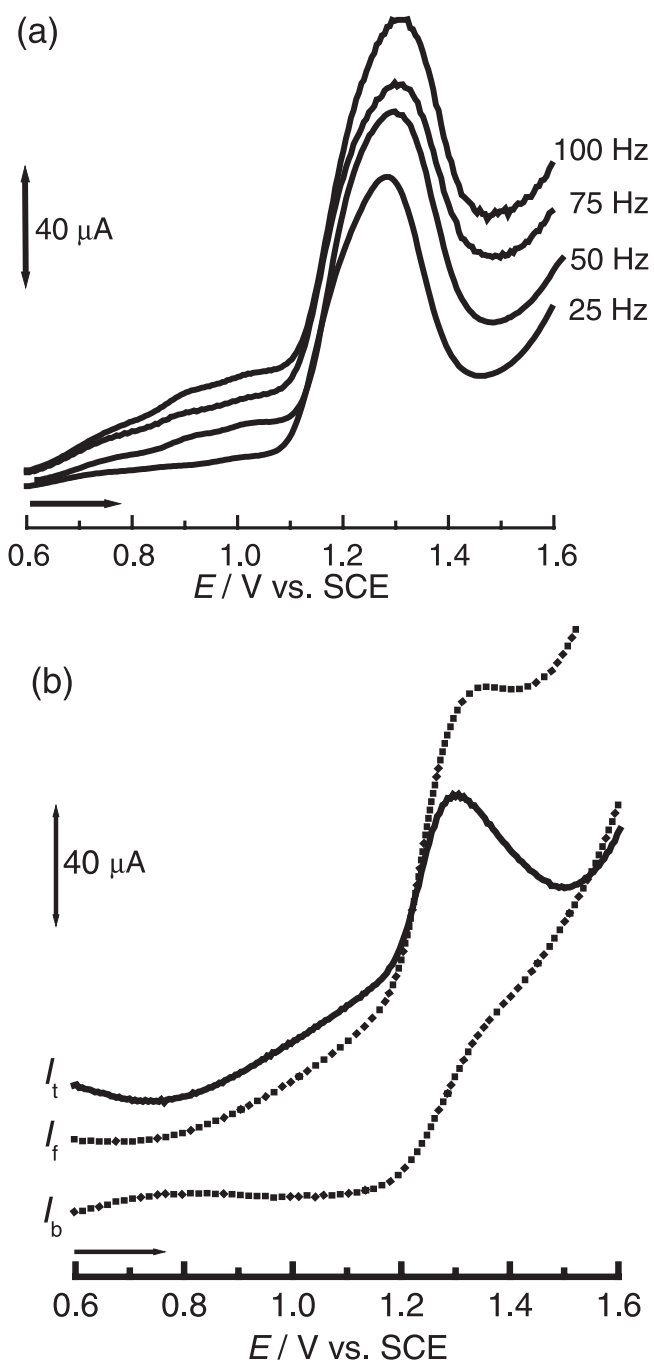

Fig. 5. Square wave voltammograms of $1 \mathrm{mM} \mathrm{Hx}$ in $0.2 \mathrm{M}$ acetate buffer (pH 4.5). (a) Frequencies 25, 50, 75 and $100 \mathrm{~Hz}$; (b) frequency $100 \mathrm{~Hz}$, $I_{\mathrm{t}}$ - total current, $I_{\mathrm{f}}$-forward current and $I_{\mathrm{b}}$-backward current.

cerning Hx, Fig. 5, the peak potential is $+1.30 \mathrm{~V}$ and the peak width at half height is $\sim 200 \mathrm{mV}$, whereas for IMP, Fig. 6, the peak potential is $+1.52 \mathrm{~V}$ and the peak width at half height is $\sim 50 \mathrm{mV}$ at all frequencies investigated. Thus, the oxidation mechanisms for each molecule have different rates.

In the case of $\mathrm{Hx}$, the examination of the forward and backward components of the total current in the square wave voltammograms (Fig. 5b) explains the broadness of the peak corresponding to the total current due to the contributions of the separated forward and backward peaks.

Analysis of the forward and backward components of the square wave voltammograms of IMP (Fig. 6b) confirms that the electrode process is highly irreversible. The detailed mechanism is affected by the existence of the deoxyribosephosphate group substituent on the purine ring, and the oxidation of IMP, due to the substituent, is more difficult and occurs at more positive potentials.

\subsection{Electrochemical impedance spectroscopy}

Electrochemical impedance spectroscopy (EIS) was used to probe the adsorption phenomena of hypoxanthine at potentials corresponding to the oxidation wave. It was not possible to carry out EIS experiments with IMP because the oxidation occurs too close to the electrolyte decomposition wave. Fig. 7 shows complex plane impedance spectra for hypoxanthine at different applied potentials. A purely capacitive behaviour with constant phase angle characteristics is observed at potentials preceding the oxidation reaction of hypoxanthine. The shift of the angle downwards from $90^{\circ}$ with respect to the real axis is due to the roughness of the surface of the glassy carbon electrode; roughness exponents of 0.8-0.85 (angle of $\sim 80^{\circ}$ ) are commonly observed, as is the slight curvature [33]. At potentials corresponding to the oxida-
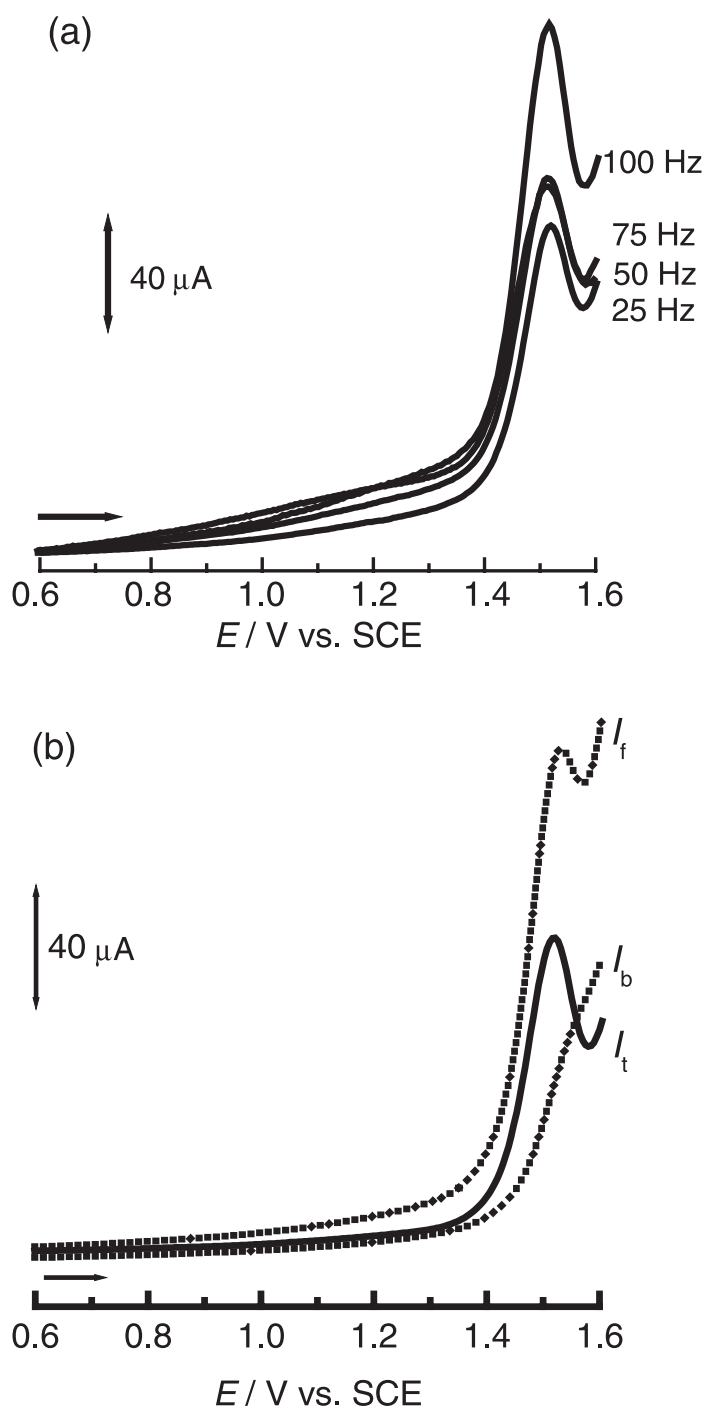

Fig. 6. Square wave voltammograms of $1 \mathrm{mM}$ IMP in $0.2 \mathrm{M}$ acetate buffer (pH 4.5). (a) Frequencies 25, 50, 75 and $100 \mathrm{~Hz}$; (b) frequency $100 \mathrm{~Hz}$, $I_{\mathrm{t}}$ - total current, $I_{\mathrm{f}}$ - forward current and $I_{\mathrm{b}}$ - backward current. 


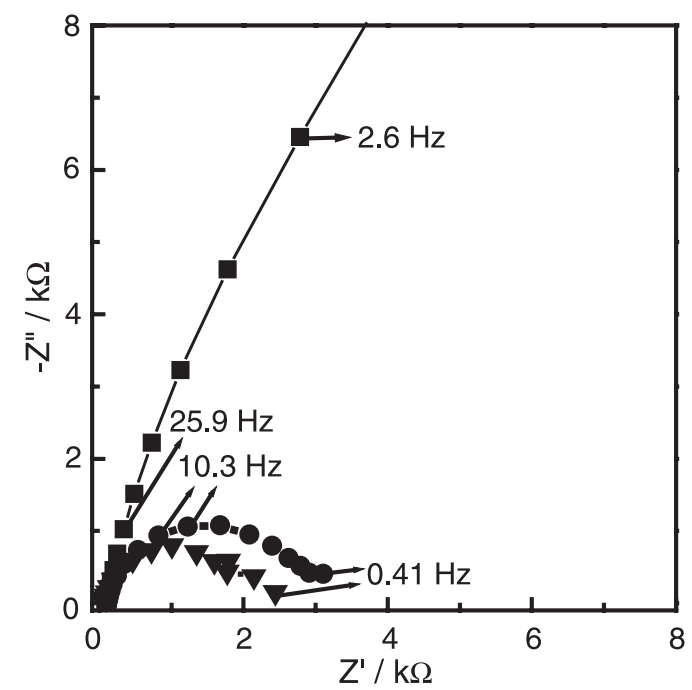

Fig. 7. Impedance spectra in the complex plane for $1 \mathrm{mM}$ hypoxanthine in $0.2 \mathrm{M}$ acetate buffer ( $\mathrm{pH} 4.5$ ) at different potentials: $0.4 \mathrm{~V}, \bullet 1.25 \mathrm{~V}, \boldsymbol{\nabla}$ $1.30 \mathrm{~V}$ vs. SCE.

tion of hypoxanthine, well-defined semicircles can be observed.

Fig. 8 shows successive impedance measurements for hypoxanthine. The increase of the semicircle diameter is due to the adsorptive process of this compound on the surface of the glassy carbon electrode. The adsorption blocks the electrode surface and makes the charge transfer for the oxidation reaction of hypoxanthine difficult. A similar behaviour has been observed for guanine and adenine [34]. The charge transfer resistance, $R_{\mathrm{ct}}$, was calculated by fitting the spectra to a simple equivalent circuit consisting of $R_{\mathrm{ct}}$ in parallel with a CPE. The values obtained are plotted as a function of scan number in the inset of Fig. 8. These values, of the order of kilo-ohms

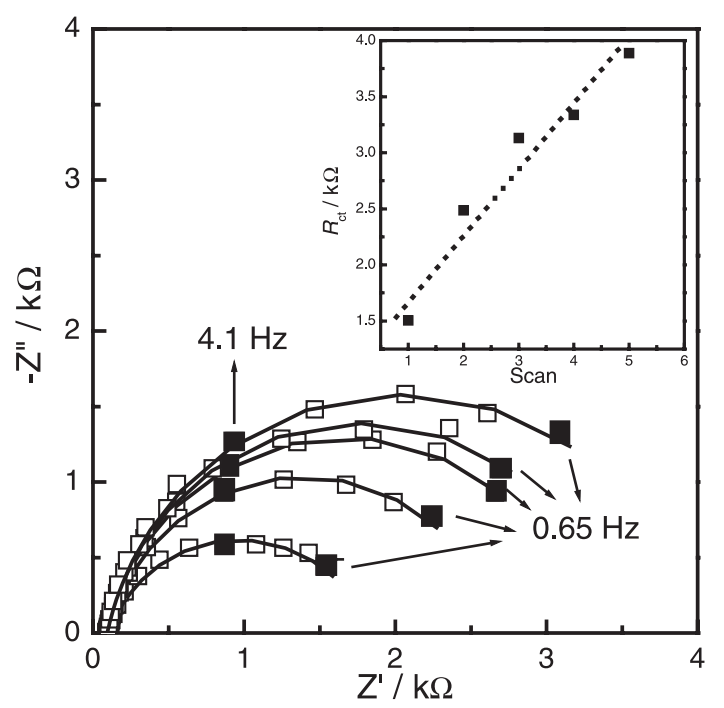

Fig. 8. Successive impedance spectra in the complex plane for $1 \mathrm{mM}$ hypoxanthine, at $1.3 \mathrm{~V}$ vs. SCE, $0.2 \mathrm{M}$ acetate buffer ( $\mathrm{pH} 4.5$ ). Inset: Charge transfer resistance, $R_{\mathrm{ct}}$, as a function of successive scans. increase almost linearly with successive scans, suggesting that saturation of the surface is far from complete after five scans and gives an idea of the kinetics of adsorption, because the recording of each impedance spectrum takes around $10 \mathrm{~min}$.

Fig. 9a shows the effect of adsorption on the impedance spectra before and after applying the potential at which hypoxanthine is oxidised and Fig. $9 \mathrm{~b}$ before and after maintaining the electrode at open circuit in the hypoxanthine solution. In Fig. 9a, when applying a potential of 1.3 $\mathrm{V}$ in the zone of oxidation, $R_{\mathrm{ct}}$ increases to three times its initial value, from 1.8 to $6.4 \mathrm{k} \Omega$. However, at open circuit, there is only a very small increase in $R_{\mathrm{ct}}$ (Fig. 9b) from 1.4 to $1.9 \mathrm{k} \Omega$. This demonstrates clearly that adsorption is not spontaneous and that it is necessary to apply a potential for it to occur, and is thus associated with the oxidation process as is also seen with other purine bases [34].
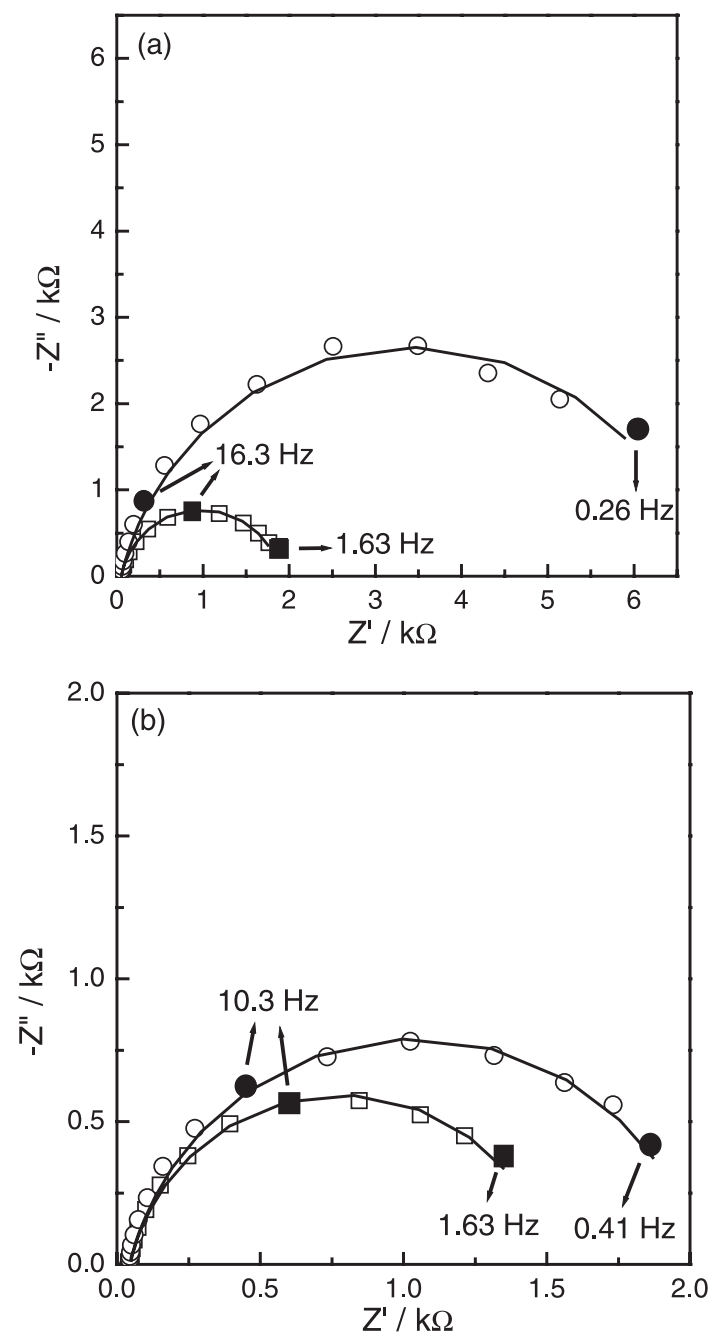

Fig. 9. Impedance spectra in the complex plane for $1 \mathrm{mM}$ hypoxanthine at $1.3 \mathrm{~V}$ vs. SCE, $0.2 \mathrm{M}$ acetate buffer (pH 4.5). (a) Before ( $\square$ ) and after (O) applying a conditioning potential of $+1.3 \mathrm{~V}$ during $30 \mathrm{~min}$. (b) Before ( $\square$ ) and after $(\mathrm{O})$ leaving the electrode at open circuit during $30 \mathrm{~min}$ in solution. 


\section{Conclusions}

The voltammetric study undertaken shows that both inosine $5^{\prime}$-monophosphate and hypoxanthine adsorb onto the surface of glassy carbon electrodes. Although the oxidation of both IMP and Hx occurs at similar potentials, the detailed mechanism of the first step in the oxidation is different for the two molecules as demonstrated by square wave voltammetry, with the oxidation of IMP being much faster. At $\mathrm{pH}$ values close to neutral, the recorded oxidation currents are also higher.

Impedance spectra show the kinetics of hypoxanthine adsorption on the surface of the glassy carbon electrode, with only slight adsorption observed under open circuit conditions, it being necessary to apply a potential corresponding to $\mathrm{Hx}$ oxidation. This suggests that the adsorbed species are electroactive oligomer products of oxidation which block the electrode surface.

The clarification of the mechanism of oxidation in this work has shown the possibility of detection of these compounds in aqueous media and the usefulness of differential pulse and square wave voltammetry as well as electrochemical impedance for probing the electrode process.

\section{Acknowledgements}

Financial support from Fundação para a Ciência e Tecnologia (FCT), Portugal project POCTI (co-financed by the European Community fund FEDER), ICEMS (Research Unit 103), and European Projects ERB-ICT15-CT960804 and QLK3-2000-01311, is gratefully acknowledged.

\section{References}

[1] B.-O. Kassemsarn, P. Sang, J. Murray, N.R. Jones, Nucleotide degradation in the muscle of iced haddock (Gadus aglefinus), lemon sole (Pleuronectes microcephalus), and plaice (Leuronectes platessa), J. Food Sci. 28 (1963) 28-37.

[2] D.L. Smith, P.J. Elving, Analytical utilization of the polarographic and voltammetric behavior of purines and pyrimidines, Anal. Chem. 34 (1962) 930-936.

[3] L. Havran, L. Trnková, O. Dracka, Inosine reduction study at low $\mathrm{pH}$ by a combination of electrochemical methods, J. Electroanal. Chem. 454 (1998) 65-73.

[4] M. Rueda, A. Mota, M.L.S. Gonçalves, I. Navarro, F. Prieto, Interfacial properties of hypoxanthine adsorbed at the mercury / electrolyte interface, J. Electroanal. Chem. 451 (1997) 257-267.

[5] E. Palecek, Reaction of nucleic-acid bases with the mercury-electrode - determination of purine derivatives at submicromolar concentrations by means of cathodic stripping voltammetry, Anal. Biochem. 108 (1980) 129-138.

[6] M.S. Ibrahim, M.E. Ahmad, Y.M. Temerk, A.M. Kawde, Adsorptive stripping voltammetric behaviour of hypoxanthine, Anal. Chim. Acta 328 (1996) 47-52.

[7] M.M. Correia dos Santos, C.M.L. Freire Lopes, M.L. Simões Gonçalves, Voltammetric studies of purine bases and purine nucleosides with copper, Bioelectrochem. Bioenerg. 39 (1996) 55-60.

[8] E.T.G. Cavalheiro, K.A. El-Nour, A. Brajter-Toth, Possibilities of the use of fast scan voltammetry in simultaneous determination of purines at carbon fiber ultramicroelectrodes, J. Braz. Chem. Soc. 11 (2000) $512-515$

[9] J.-M. Zen, Y.-Y. Lai, G. Ilangovan, A.S. Kumar, Electrocatalytic oxidation of hypoxanthine on a Nafion/lead ruthenium oxide pyrochlore modified electrode, Electroanalysis 12 (2000) 280-286.

[10] J.-M. Zen, Y.-Y. Lai, H.-H. Yang, A.S. Kumar, Multianalyte sensor for the simultaneous determination of hypoxanthine, xanthine and uric acid based on a preanodized nontronite-coated screen-printed electrode, Sens. Actuators, B 84 (2002) 237-244.

[11] X. Cai, K. Kalcher, C. Neuhold, Simultaneous determination of uric acid, xanthine and hypoxanthine with an electrochemically pretreated carbon paste electrode, Fresenius' J. Anal. Chem. 348 (1994) 660-665

[12] E.T.G. Cavalheiro, A. Brajter-Toth, Amperometric determination of xanthine and hypoxanthine at carbon electrodes. Effect of surface activity and the instrumental parameters on the sensitivity and the limit of detection, J. Pharm. Biomed. Anal. 19 (1999) 217-230.

[13] E. Watanabe, S. Tokkimatsu, K. Toyama, I. Karube, H. Matsuoka, S. Suzuki, Simultaneous determination of hypoxanthine, inosine, inosine-5'-phosphate and adenosine-5'-phosphate with a multielectrode enzyme sensor, Anal. Chim. Acta 164 (1984) 139-146.

[14] A. Mulchandani, J.H.T. Luong, K.B. Male, Development and application of a biosensor for hypoxanthine in fish extract, Anal. Chim. Acta 221 (1989) 215-222.

[15] E. Gonzalez, F. Pariente, E. Lorenzo, L. Hernandez, Amperometric sensor for hypoxanthine and xanthine based on the detection of uric acid, Anal. Chim. Acta 242 (1991) 267-273.

[16] H. Okuma, H. Takahashi, S. Sekimukai, K. Kawahara, R. Akahoshi, Mediated amperometric biosensor for hypoxanthine based on a hydroxylmethylferrocene-modified carbon paste electrode, Anal. Chim. Acta 244 (1991) 161-164.

[17] S. Hu, C.-C. Liu, Development of a hypoxanthine biosensor based on immobilized xanthine oxidase chemically modified electrode, Electroanalysis 9 (1997) 372-377.

[18] M.-A. Carsol, G. Volpe, M. Mascini, Amperometric detection of uric acid and hypoxanthine with xanthine oxidase immobilized and carbon based screen-printed electrode. Application for fish freshness determination, Talanta 44 (1997) 2151-2159.

[19] G. Cayuela, N. Peña, A.J. Riviejo, J.M. Pingarrón, Development of a bienzyme graphite-Teflon composite electrode for the determination of hypoxanthine in fish, Analyst 123 (1998) 371-377.

[20] S. Ghosh, D. Sarker, T.N. Misra, Development of an amperometric enzyme electrode biosensor for fish freshness detection, Sens. Actuators, B 53 (1998) 58-62.

[21] J. Niu, J.Y. Lee, Bulk-modified amperometric biosensors for hypoxantine based on sol-gel technique, Sens. Actuators, B 62 (2000) $190-198$.

[22] S. Hu, C. Xu, J. Luo, J. Luo, D. Cui, Biosensor for detection of hypoxanthine based on xanthine oxidase immobilised on chemically modified carbon paste electrode, Anal. Chim. Acta 412 (2000) $55-61$.

[23] L. Mao, K. Yamamoto, Amperometric on-line sensor for continuous measurement of hypoxanthine on osmium-polyvinylpyridine gel polymer and xanthine oxidase bienzyme modified glassy carbon electrode, Anal. Chim. Acta 415 (2000) 143-150.

[24] F. Xu, L. Wang, M. Gao, L. Jin, J. Jin, Amperometric sensor for glucose and hypoxanthine based on a $\mathrm{Pd}-\mathrm{IrO}_{2}$ modified electrode by a co-crosslinking bienzymic system, Talanta 57 (2002) 365-373.

[25] H. Okama, E. Watanabe, Flow system for freshness determination based on double multi-enzyme reactor electrodes, Biosens. Bioelectron. 17 (2002) 367-372.

[26] A.R. Katritzky (Ed.), Physical Methods in Heterocyclic Chemistry, Chapter I, Table XVI, Academic Press, New York, 1963.

[27] C.M.A. Brett, A.M. Oliveira Brett, S.H.P. Serrano, On the adsorption and electrochemical oxidation of DNA at glassy carbon electrodes, J. Electroanal. Chem. 366 (1994) 225-231. 
[28] A.C. Conway, R.N. Goyal, G. Dryhurst, Electrochemical oxidation of hypoxanthine, J. Electroanal. Chem. 123 (1981) 243-264.

[29] R.N. Goyal, A. Mittal, S. Sharma, Simultaneous voltammetric determination of hypoxanthine, xanthine, and uric acid, Electroanalysis 6 (1994) 609-611.

[30] A.M. Oliveira Brett, S.H.P. Serrano, The electrochemical oxidation of DNA, J. Braz. Chem. Soc. 6 (1995) 97-100.

[31] E. Palecek, in: G. Milazzo (Ed.), Topics in Bioelectrochemistry and Bioenergetics, vol. 5, Wiley, London, 1983, p. 65.
[32] A.M. Oliveira Brett, F.M. Matysik, Voltammetric and sonovoltammetric studies on the oxidation of thymine and cytosine at a glassy carbon electrode, J. Electroanal. Chem. 429 (1997) 95-99.

[33] C.M.A. Brett, A.M. Oliveira Brett, S.H.P. Serrano, An EIS study of DNA-modified electrodes, Electrochim. Acta 44 (1999) 4233-4239.

[34] A.M. Oliveira Brett, L.A. Silva, C.M.A. Brett, Adsorption of guanine, guanosine, and adenine at electrodes studied by differential pulse voltammetry and electrochemical impedance, Langmuir 18 (2002) $2326-2330$. 